Marluce Auxiliadora Borges Glaus Leão Ludimila Santos Silva ${ }^{2}$

\section{Vivências de trabalhadores com deficiência: uma análise à luz da Psicodinâmica do Trabalho*}

\author{
Life experiences of disabled workers: An analysis using \\ Psychodynamics of Work
}

${ }^{1}$ Psicóloga, Docente do Curso de Psicologia na Universidade de Taubaté, Taubaté, SP, Brasil.

${ }^{2}$ Psicóloga pela Universidade de Taubaté, Taubaté, SP, Brasil.

*Trabalho de Conclusão de Curso de Graduação em Psicologia da segunda autora, orientada pela primeira; sem fomento institucional.

Trabalho apresentado no II Congresso Brasileiro de Psicologia da Saúde; Uberlândia, MG, agosto/2010; resumo expandido publicado nos anais com o nome Saúde mental de indivíduos com deficiência inseridos no mercado formal de trabalho: contribuições da Psicologia.

\section{Contato:}

Marluce Auxiliadora Borges Glaus Leão Rua Rosa Barbieri Paiotti, 244 - Urbanova, São José dos Campos, SP

CEP: 12244-050

E-mail:

mgleao08@gmail.com

\section{Resumo}

As organizações de trabalho indicam dificuldades em cumprir a lei de contratação de trabalhadores com deficiência. A gestão dos indivíduos com deficiência inseridos no mercado formal envolve articulação entre suas vivências e as demandas desse contexto. Este estudo investigou as vivências subjetivas de deficientes auditivos e deficientes físicos de uma empresa de grande porte no Vale do Paraíba Paulista, em 2010. Trata-se de uma pesquisa qualitativa por meio de seis estudos de casos, utilizando-se entrevistas, cuja análise de conteúdo foi feita à luz da Psicodinâmica do Trabalho. Os resultados apontaram aspectos de sofrimento no trabalho oriundos do desgaste físico ou psíquico e da falta de reconhecimento no trabalho, que reativam estratégias defensivas frente às situações adversas, como a concepção de deficiência vigente nesse contexto. Como aspectos de prazer, estar empregado gera autonomia e senso de competência. Conclui que as vivências de sofrimento desses deficientes sobrepõem-se às de prazer no trabalho e que a visão de deficiência que prevalece dificulta seu crescimento profissional e uma legítima inclusão ao trabalho. Sugere um melhor equacionamento dos processos de gestão na organização, considerando a visão desses trabalhadores, para a ressignificação das concepções de deficiência, o efetivo cumprimento da lei e ainda minimizar os riscos à sua saúde mental.

Palavras-chave: saúde mental; psicodinâmica do trabalho; indivíduos com deficiência; mercado de trabalho.

\begin{abstract}
Employers report difficulties in complying with the legislation on hiring disabled workers. Their management includes the integration between their life experiences and the formal market demands. This study investigated the subjective experiences of workers with hearing and physical disabilities of a large company in Vale do Paraiba, state of São Paulo, Brazil, in 2010. It was a qualitative research with six case studies, using semi-structured interviews, which contents were analyzed according to Psychodynamics of Work. Results pointed out aspects of workers' suffering due to their physical or psychological distress and as a consequence of lack of recognition at work. These situations led them to adopt defensive attitudes when facing adverse situations, such as prejudices regarding disability that prevail in this context. Aspects of pleasure were also presented: being employed developed autonomy and sense of competence. The study concludes that suffering was superimposed upon pleasure among these workers, and that the current view of disability was an obstacle for their professional growth and real inclusion in the market. It suggests an improvement in the managing processes by taking into consideration the disabled workers' view to resignify disability concepts, to effectively enforce legislation, and to minimize mental health risks among them.
\end{abstract}

Keywords: mental health; psychodynamics of work; people with disabilities; job market. 


\section{Introdução}

A contratação de indivíduos com deficiência pelo mercado formal de trabalho é um fenômeno recente na sociedade, que aos poucos indica reconhecê-los como cidadãos de direitos e deveres. Uma visão panorâmica sobre alguns parâmetros oficiais mostra-se importante para pensar a articulação desta questão sob vários prismas.

Testemunha-se que as diversas modalidades de deficiência - física, motora, mental ou, ainda, sensorial, podem gerar dificuldade ou impossibilidade de execução de atividades comuns a outros indivíduos, resultando em barreiras na vida cotidiana, como exemplo, a manutenção do trabalho. Diante disso, no Brasil, a Constituição Federal de 1998 passou a dispensar um tratamento diferenciado aos indivíduos com deficiência. Esta questão foi posteriormente resguardada pela Lei 8.213/91, dispondo em seu Art. 93 que o setor privado é obrigado a destinar 2 a $5 \%$ de seus postos de trabalho a indivíduos com deficiência, desde que habilitados, de forma proporcional ao número total de empregados: de 100 a 200 empregados $-2 \%$; de 201 a $500-3 \%$; de 501 a $1000-4 \%$ e de 1001 em diante - 5\% (BRASIL, 1991).

Conforme o censo demográfico do Instituto Brasileiro de Geografia e Estatística (2011, p. 1), "o total de pessoas que declararam possuir pelo menos uma deficiência severa no país foi de 17.777.080, representando $6,7 \%$ da população total".

O Relatório Mundial sobre a Deficiência, elaborado pela Organização Mundial da Saúde e pelo Banco Mundial em 2011 (SÃO PAULO [ESTADO], 2012, p. 4), lembra que a Convenção das Nações Unidas sobre os Direitos das Pessoas com Deficiência (CDPD) reconhece a deficiência como:

[...] um conceito em evolução, mas realça também [...] que resulta da interação entre pessoas com deficiência e barreiras comportamentais e ambientais que impedem sua participação plena e eficaz na sociedade de forma igualitária. (p. 4)

No Brasil, o Decreto nº 6.949 (BRASIL, 2009), que promulga a Convenção Internacional sobre os Direitos das Pessoas com Deficiência, considera a pessoa com deficiência:

[...] aquela que tem impedimentos de longo prazo de natureza física, mental, intelectual ou sensorial, os quais, em interação com diversas barreiras, podem obstruir sua participação plena e efetiva na sociedade em igualdade de condições com as demais pessoas. (p. 1)

Uma visão ecológica da deficiência pode ser observada na definição da Organização Internacional do Trabalho (OIT), considerando a pessoa com deficiência aquela:
[...] cujas perspectivas de obter emprego apropriado, reassumi-lo, mantê-lo e nele progredir são substancialmente reduzidas em virtude de deficiência física, auditiva, visual, mental ou múltipla devidamente reconhecida, agravadas pelas dificuldades locais de inclusão no mundo do trabalho [...] (SECRETARIA INTERNACIONAL DO TRABALHO, 2006, p. 5).

Suzano et al. (2008), em revisão da literatura nacional sobre a inserção de pessoas com deficiência no mercado de trabalho e a respeito do conceito de deficiência, atestam as inúmeras nomenclaturas utilizadas, inclusive a de deficiente; atualmente em desuso. Como resultados apontam ter havido:

[...] um aumento da produção científica a respeito da pessoa com deficiência, principalmente com relação à gestão da diversidade [...] as dificuldades que enfrentam para se inserir no mercado de trabalho, o estigma e a gestão delas dentro das organizações [...] a questão da pessoa com deficiência ser reduzida à deficiência que possui e não às suas potencialidades e possibilidades de trabalho [...] as barreiras arquitetônicas [...]. (p. 33)

Observa-se, ainda, que a demanda das organizações de trabalho para contratação de trabalhadores com deficiência, mesmo que seja para atender aos dispositivos legais, não é diferente de qualquer outro tipo de pessoa, ou seja, acompanhada por conflitos de interesses entre trabalhadores e contratantes representando um desafio para as políticas de gestão. Em relação às condições objetivas de trabalho, dadas às barreiras impostas pelo ambiente social, a utilização de equipamentos diversos nem sempre configura uma situação fácil de ser discutida e redimensionada. Por extensão, as vivências subjetivas desses indivíduos sugerem desconsideração enquanto trabalhadores submetidos a contextos que impactam seus limites e potencialidades.

Esta questão hoje remete a pensar na inclusão como perspectiva social da deficiência, compreendida como "processo pelo qual a sociedade se adapta para poder incluir, em seus sistemas sociais gerais, indivíduos com deficiência e, simultaneamente, estes se preparam para assumir seus papéis na sociedade" (SASSAKI, 1999, p. 41). Em relação às organizações formais de trabalho, essa inclusão relaciona-se à eliminação de todas as barreiras físicas e atitudinais para que os deficientes tenham acesso ao mundo do trabalho e ao desenvolvimento pessoal, social, educacional e profissional (OLIVEIRA; ARAÚJO; ROMAGNOLI, 2006).

A lógica da inclusão na visão de Carvalho-Freitas (2009, p. 135):

[...] tem como premissa substituir a busca por um homem ideal e padronizado pela adequação das condições e práticas de trabalho, de forma a acolher as diferenças. Ainda que a inclusão dessas pessoas mantenha as contradições próprias às relações de 
trabalho capitalistas, transformando as diferenças em mercadoria e em diferencial competitivo para as organizações, ela abre possibilidades para um ordenamento social menos discriminatório. (grifo das autoras)

Esta perspectiva guarda estreita relação com o campo de investigações sobre a gestão da diversidade e a revisão dos processos de trabalho, particularmente nas empresas, tendo em vista a situação de transição do mundo contemporâneo:

[...] que de um lado pressionava por processos mais flexíveis para garantir a agilidade produtiva e a competitividade e que, por outro lado, exigia uma consciência e ações no sentido da inclusão da diversidade no trabalho que ganharam o nome de responsabilidade social. (RIBEIRO; RIBEIRO, 2008, p. 125)

Estes autores apresentam a definição de diversidade de Carrel e Mann (1995 apud RIBEIRO; RIBEIRO, 2008) e Friday e Friday (2003 apud RIBEIRO; RIBEIRO, 2008) como:

[...] qualquer atributo visível ou invisível saliente de uma pessoa que o faça ser percebido como diferente dos outros (raça, gênero, etnia, nacionalidade, religião, idade, atributos físicos). (p. 126)

Citam ainda que, para Smith, Smith e Markham (2000, apud RIBEIRO; RIBEIRO, 2008), diversidade é a:

[...] presença da diferença numa estrutura pretensamente homogênea ou misto de pessoas com identidades grupais diferentes no interior de um mesmo grupo ou espaço psicossocial. (p. 126)

Em se tratando da gestão da diversidade com foco nos indivíduos com deficiência, Carvalho-Freitas $(2009$, p. 123) ressalta a importância de investigações sobre a nova realidade das organizações de trabalho, apontando que os estudos:

[...] têm indicado três dificuldades para inserir e gerir o trabalho dessas pessoas: as formas como os gestores veem a deficiência, a adequação das condições e práticas de trabalho por parte das empresas e a necessidade de avaliar a satisfação das pessoas com deficiência inseridas no mercado.

Pesquisas com diferentes desenhos teórico-metodológicos apontam os obstáculos encontrados pelos deficientes para ingressar, manter ou crescer dentro das empresas, inclusive as atitudes contraditórias por parte delas. Como exemplo, citam as dificuldades relacionadas às barreiras à cidadania, como as arquitetônicas e para se candidatar a um emprego; discriminação no pleito à uma vaga e no ambiente de trabalho; expectativas de crescimento profissional associada a melhores salários (ALMEIDA; CARVALHO-FREITAS; MARQUES, 2008; NOHARA; ACEVEDO; FIAMMETTI, 2008); desconhecimento dos direitos e associação do trabalho com a autoestima (CARVALHO-FREITAS; MARQUES, 2008). Sobre os aspectos positivos, aparecem percepções de autonomia e dignidade e de valorização social determinada pela conquista do emprego (NOHARA; ACEVEDO; FIAMMETTI, 2008). Coimbra e Goulart (2008) apontam, ainda, as necessidades de adequação das práticas e condições de trabalho, especialmente em relação à necessidade de sensibilização das pessoas nesse contexto, para uma legítima inserção dos trabalhadores com deficiência.

Tendo em vista, portanto, o panorama atual do mundo do trabalho e suas necessidades para acomodar as diferenças, a centralidade que o trabalho ocupa na vida dos indivíduos e a importância de a gestão organizacional alinhar os interesses econômicos e psicossociais, considera-se relevante compreender como ocorrem as relações objetivas e subjetivas de trabalhadores com deficiência no contexto formal de trabalho em que estão inseridos.

Em relação às questões subjetivas, como exemplo, as vivências de prazer e/ou sofrimento psíquico advindas do trabalho, observa-se nos últimos anos um grande interesse nos estudos e publicações relacionados aos vínculos entre trabalho e saúde/ doença mental e bem estar frente às novas estruturas de organização do trabalho, especialmente no tocante aos desafios impostos às políticas públicas (SELIGMANN-SILVA et al., 2010). Esse interesse pode ser creditado a fatores como o número crescente de transtornos mentais e do comportamento associados ao trabalho constatado nas estatísticas oficiais e não oficiais (SELIGMANN-SILVA et al., 2010); a uma releitura de teorias clássicas no interior da Psicologia, reafirmando a importância do trabalho na constituição do sujeito e na sua inserção social como estratégia de saúde, e associação ao adoecimento; bem como a abertura do campo da saúde do trabalhador à Psicologia consolidada por dispositivos legais (JACQUES, 2003).

No conjunto das teorias que enfatizam o papel do trabalho no processo de adoecimento mental, a abordagem teórico-metodológica da Psicodinâmica do Trabalho, referendada por fundamentos psicanalíticos, privilegia o estudo da normalidade sobre a patologia, propondo, na inter-relação saúde/doença mental e trabalho, interseções com a Psicologia, particularmente, com a Psicologia Social.

Esta abordagem tem como principal expoente o francês Christophe Dejours e a introdução do conceito de "sofrimento psíquico como uma vivência subjetiva intermediária entre a doença mental descompensada e o conforto ou bem-estar psíquico" (DEJOURS; ABDOUCHELY, 1994, p. 124) que suscita a utilização de "estratégias defensivas, construídas, organizadas e gerenciadas coletivamente” (p. 127), passíveis de compreensão a partir de métodos qualitativos. Para Dejours (2007 apud MENDES, 2008, p. 
14), o trabalho é um operador de saúde, "faz parte da constituição do sujeito, implica ação do sujeito sobre a realidade, sendo o real o que se faz conhecer pelo sujeito".

A utilização do referencial da Psicodinâmica do Trabalho em inúmeros estudos e pesquisas brasileiros tem dado visibilidade ao mal-estar de diferentes categorias profissionais, oriundo das condições ergonômicas do trabalho prescrito e do trabalho real; de aspectos relacionados à dimensão organizacional centralizada na divisão de tarefas, nas relações de produção e na organização do trabalho, como ritmo, jornada, hierarquia, responsabilidade e controle a que os indivíduos estão submetidos (SELIGMANN-SILVA, 1992; LIMA JÚNIOR; ESTHER, 2001; BARROS; MENDES, 2003; MENDES; MORRONE, 2002; 2004; SANTOS, 2006; MERLO; MENDES, 2007).

Há que lembrar, conforme Antloga e Mendes (2009), três fases distintas da Teoria Psicodinâmica. A primeira, durante a década de 80 , de estudos sobre o sofrimento e as estratégias defensivas no confronto com a organização do trabalho; a segunda, até o início da década de 90, considerando as vivências de prazer e de um trabalho saudável e a terceira, focalizando o trabalho como lócus de construção da identidade do trabalhador, por meio da dinâmica de reconhecimento, prazer e sofrimento, mediante as novas estruturas de organização do trabalho.

Estas questões sustentam esta pesquisa no propósito de conhecer aspectos da psicodinâmica de trabalhadores com deficiência e suas inter-relações com o ambiente formal de trabalho em que estão inseridos. Nesse sentido, estabeleceu-se como objetivo investigar as vivências subjetivas daqueles com deficiência auditiva e outros com deficiência física utilizando-se o referencial da Teoria Psicodinâmica do Trabalho.

\section{Método}

Trata-se de um estudo qualitativo a partir de seis estudos de casos, realizado junto a trabalhadores com deficiência auditiva ou física, de ambos os sexos, independentemente dos cargos que desempenhavam em uma empresa multinacional de grande porte, do setor de energia, localizada em cidade do interior do Vale do Paraíba Paulista.

À época da coleta de dados, dezembro de 2010, havia 82 deficientes (somando-se os físicos e os auditivos) trabalhando nas áreas administrativa ou operacional (do total de 1882 funcionários). Optou-se nesta pesquisa por uma amostra de conveniência, e como critérios de elegibilidade aqueles que trabalhavam há pelo menos um ano em cargos da es- trutura administrativa (pela disponibilidade da área em liberar os funcionários para a pesquisa); os que não apresentassem deficiência severa inviabilizando a coleta das informações; consentissem em participar; e ainda o critério de saturação dos dados. Nesse sentido, foram entrevistados quatro deficientes físicos e dois auditivos.

Em relação à metodologia utilizada, mais que os fatos em si do cotidiano no trabalho, valoriza-se na coleta dos dados a versão que o coletivo de trabalhadores lhes confere, embora as questões objetivas do contexto desempenhem também "um papel relevante na expressão do sofrimento e do prazer no trabalho" (DEJOURS, 2011a, p. 127) Para capturar essas vivências foram utilizados como instrumentos a observação sistemática dos aspectos do cotidiano do pesquisado, visando a descrição e registro dos processos e do contexto objetivo de seu trabalho e entrevistas individuais semiestruturadas, tendo em vista os limites organizacionais para entrevistas coletivas, além das singularidades dos participantes em termos da deficiência que apresentavam. Essas entrevistas tiveram poucos tópicos, permitindo uma relativa flexibilidade ao pesquisador para abordar o tema em pauta. Foram investigadas as relações sociais de trabalho (processo de integração, interações hierárquicas e com os colegas, reconhecimento); as condições de trabalho (ambiente físico, suporte organizacional, instrumentos e equipamentos, política de pessoal); a organização do trabalho (divisão do trabalho, controle, ritmo, responsabilidade, normas e regras, produtividade esperada); as situações de trabalho e respectivas vivências subjacentes.

O constructo teórico-metodológico de Dejours serviu como guia para perceber as semelhanças e singularidades dos relatos dos trabalhadores com deficiência sobre a complexidade das suas interações no contexto de trabalho e os mecanismos psicológicos acionados frente às situações adversas.

Após a aprovação do projeto de pesquisa pelo Comitê de Ética em Pesquisa da Universidade de Taubaté (Protocolo no 566/09), iniciou-se o contato com a empresa visando sua anuência. Em seguida, foi feita uma aplicação piloto por meio de entrevista e observação junto a um dos participantes - um trabalhador deficiente auditivo em seu ambiente de trabalho, para eventuais ajustes nos instrumentos e depois a coleta total dos dados. Os pesquisados foram informados previamente sobre as questões éticas da pesquisa como sigilo de sua identidade, informações fornecidas, ciência dos objetivos do estudo e acesso aos resultados, para posterior assinatura em um termo de consentimento livre e esclarecido. 
Os dados coletados foram submetidos à análise de conteúdo de Bardin (1977), que considera a comunicação como um processo que tem a palavra como mediadora do sentido, sendo reunidos em categorias baseadas na recorrência dos temas verbalizados pelos entrevistados, e os resultados discutidos à luz da Teoria Psicodinâmica do Trabalho (DEJOURS; ABDOUCHELY, 1994).

\section{Resultados e discussão}

Foram pesquisados seis trabalhadores com deficiência atuantes na área administrativa, constatando-se que suas vivências apresentam semelhanças sobre a natureza, o conteúdo das tarefas e processo de integração. Desenvolvem atividades de escritório, atendimento telefônico e reprodução xerográfica, em setores diferentes, compartilhando parcialmente os espaços físicos. Trabalham junto a funcionários com e sem deficiência e quando realizam as mesmas atribuições, têm a mesma remuneração.

Pelos dados da observação sistemática caracterizou-se o contexto de trabalho destes trabalhadores como típicos de uma organização de filiação Taylorista-fordista, com fragmentação e padronização das tarefas, controle do ritmo e tempo de trabalho, pressões, sobrecarga e monotonia. As condições objetivas de trabalho aparecem como elemento de preocupação desta empresa para facilitar a integração do trabalhador com deficiência, com relativa adequação dos aspectos físicos do contexto, e cuidado com questões ergonômicas, instrumentais e de acessibilidade. Há que destacar: espaço físico, mobiliário e equipamentos parcialmente adaptados às necessidades desses trabalhadores; portas que facilitam o trânsito de cadeirantes; coberturas contra o sol/chuva entre os prédios da empresa; rampas e facilidade de acesso entre o estacionamento dos ônibus e o local de trabalho; áreas de descanso e lazer acessíveis.

No processo de análise de conteúdo, o conjunto dos relatos apontou vivências relacionadas ao trabalho e às formas de lidar com as adversidades, possibilitando a emergência das categorias: desgaste físico e/ou psíquico, reconhecimento no trabalho e estratégias de enfrentamento, focalizadas a seguir, embora o caráter dinâmico próprio do discurso intersubjetivo nem sempre favoreça essa ordenação.

\section{Desgaste físico e/ou psíquico}

Pensar a questão da saúde mental do trabalhador com deficiência remete à discussão do processo dinâmico de saúde proposto por Dejours (1986, p. 9) concebendo "a vida das pessoas como uma sucessão de etapas e de compromissos entre sua história pas- sada e seu ambiente, para tentar transformá-lo”. O trabalho pode representar a atividade que confronta sua angústia frente aos desejos, objetivos e esperanças de bem-estar, pois, "saúde é quando ter esperanças é permitido" (p. 9). Considerando, ainda conforme esse autor, que um trabalho pode ser causa de sofrimento, mas não ter trabalho pode ser igualmente perigoso, a questão reside na dinâmica que se estabelece entre a organização do trabalho e o funcionamento psíquico do trabalhador, se ele atua como elemento estruturante ou não para sua saúde.

Os resultados encontrados corroboram os de pesquisas que apontam os obstáculos encontrados pelos deficientes para ingressar, manter ou crescer dentro das empresas, inclusive as atitudes contraditórias por parte delas (ALMEIDA; CARVALHO-FREITAS; MARQUES, 2008; NOHARA; ACEVEDO; FIAMMETT, 2008; COIMBRA; GOULART, 2008).

Embora haja nesta empresa uma política de gestão de pessoas levando em conta o trabalhador com deficiência, a ênfase do suporte recai sobre a adequação dos aspectos objetivos, entretanto, as limitações no escopo dessa política (que envolve aspectos objetivos e subjetivos) configuram-se como elementos potencializadores do sofrimento psíquico dos pesquisados. Para neutralizar esse sofrimento, há evidências de que as relações sociais atuam como estratégias de mediação, como ilustra a citação de um dos participantes deste estudo:

o encarregado já me disse que nessa função eu fui a melhor pessoa que apareceu para fazer essas atividades, porque antes eram duas pessoas para fazer o que eu faço sozinho.

As situações de desproteção do ambiente geram sofrimento físico e psíquico nesse trabalhador, sendo evidenciadas em vários relatos dos participantes:

\begin{abstract}
$\mathrm{Eu}$ acho que melhorou muito, quando eu entrei não tinham nem rampa e quando fizeram foi muito bom, como tenho problema na perna, foi ótimo, achei que foi um grande passo, por que eu andava muito [...] O chão do refeitório é muito liso principalmente em dias de chuva e o espaço é pequeno entre as mesas, sendo que, se alguém encostar no meu braço, já perco o equilíbrio, por isso é necessário muita atenção, tenho que usar bota de segurança, mas não gosto por que dói muito a perna, onde fiz uma cirurgia [...] O fluxo de pessoas é grande e me sinto insegura, segurando a bandeja sozinha e o fluxo de pessoas é grande [...] Eu ainda tenho algumas dificuldades aqui, como subir escadas quando preciso ir para outras áreas e usar o banheiro, por que aqui temos um banheiro adaptado e é longe da minha área, o banheiro normal é muito apertado, mesmo parecendo que não, mas são detalhes que fazem grande diferença.
\end{abstract}

A esses relatos, apontando o risco à integridade física, somam-se as exigências de autocontrole emocional frente às diferentes situações do cotidiano permeadas pelo preconceito, como descritas a seguir: 
O que eu já passei aqui na fábrica é ter que provar que não fui eu que errei, procurando evidências e mostrar onde estava o erro, pois sempre acham que fui eu [...] Eu entrei aqui na área da manutenção e quando o gestor mudou, fiquei sabendo que ele queria me mandar embora, mas acabei mudando de área. Fiquei muito triste, eu acho que foi preconceito [...] mas eu já estou acostumada, tem uns que acham legal, outros não gostam, outros que acham que a gente é lerdo.

Esses trabalhadores tem uma percepção clara do quanto o preconceito esbarra nos limites organizacionais do processo de gestão de pessoas com deficiência. Todavia, interferir no modo operatório parece ser ainda uma política que vai de encontro aos interesses do capital, pois, para além das medidas objetivas, o que está em jogo é o replanejamento do trabalho como fruto de negociações coletivas e cotidianas (SATO, 2002) e as matrizes interpretativas sobre a deficiência que ancoram as concepções de deficiência vigentes na empresa (CARVALHO-FREITAS; MARQUES, 2008).

A empresa está sendo pressionada a contratar um PCD [pessoa com deficiência] e automaticamente ela está sendo pressionada a aprender a lidar com eles [...] Eu acho que para a empresa nos receber foi um "baque", eles se sentiram obrigados a nos contratar, mas eu via que as empresas preferiam deficientes auditivos e aqui a maioria é físico, então já é um ponto legal. Mas, no começo com as pessoas é difícil, por que eles não estão acostumados com o que é diferente. [...] Eu vejo que nós entramos aqui para cumprir a lei. Se eu estivesse participando de uma entrevista com alguém sem deficiência, a chance dela seria muito maior, porque numa visão geral, as pessoas entendem que o deficiente é muito limitado, eles veem a questão física e não veem a capacidade que ela tem para melhorar e aprender coisa nova.

Os relatos acima indicam que nesse contexto ainda não é claro o pressuposto "de que a pessoa com deficiência deva ser incluída na sociedade e no trabalho tendo como parâmetro suas potencialidades, e que as organizações e a sociedade precisam se ajustar para garantir sua plena participação" (CARVALHO-FREITAS; MARQUES, 2008, p. 244).

É certo que "os avanços tecnológicos cada vez mais aumentam as exigências cognitivas, determinando esforços mentais sempre maiores" (SELIGMANN-SILVA, 1992, p. 75) principalmente quando atrelados à dimensão temporal. Nesse sentido, as pressões por produtividade provocam desgaste, repercutindo em termos de fadiga e irritabilidade, mas as vivências desse trabalhador não são homogêneas.

Alguns ficam revoltados com essa situação [...] Pressão eu considero bastante, por que sento do lado do meu gestor e ele cobra bastante. No começo eu ficava apavorada, mas fui conversando com ele que eu tinha que fazer mais devagar e ele foi acostumando [...] É uma área que tem muita pressão, mas eu sempre consegui cumprir o prazo, por que não é um ser- viço complicado, é bem tranquilo, é um serviço com grau de dificuldade pequeno e por achar simples eu não acho que sou tão pressionado.

Constata-se o controle sobre o trabalho como fator importante na subjetividade do trabalhador, seja o que exerce sobre suas atividades - correspondendo aos seus níveis de autonomia, ou àquele a que é submetido como assalariado - enquanto forma de dominação. Os pesquisados ilustram essa questão apontando a incoerência entre o conteúdo da tarefa e suas aspirações, o que sugere ativar uma situação de medo e consequente emergência do sofrimento, podendo se refletir em sintomas como ansiedade e insatisfação (DEJOURS, 1992), ou seja, o desgaste ocorre pelas contradições entre o trabalho real e o prescrito pela organização mobilizando as relações intersubjetivas e ameaçando as expectativas de contribuição-retribuição do trabalhador. Frente à sua incapacidade de executar o modo operatório prescrito pelo trabalho, reativa a estrutura defensiva para assegurar "uma adaptação aos riscos, impedindo, parcialmente ao menos, a tomada de consciência da relação de exploração" (DEJOURS, 2011b, p. 172) à qual está exposto.

Tenho muita dificuldade com telefone, mas tenho que atender mesmo assim, por que ela (gestora) diz que faz parte do trabalho [...] A maior dificuldade que tive é que ele (gestor) não entendia que eu não podia digitar com a mão esquerda, ele dizia que eu precisava tentar digitar com as duas mãos e insistia muito, eu até tentei, mas é muito difícil para mim e acho que ele cansou de falar, porque parou de exigir isso $[\ldots]$

Fica patente também, a vivência de monotonia, o quanto o conteúdo das atividades não sugere ser significativo para esse trabalhador, não contribuindo como elemento estruturante de sua identidade (DEJOURS, 1992; SELIGMANN-SILVA et al., 2010).

$\mathrm{Eu}$ gosto do que faço, mas acho que é uma coisa muito repetitiva [...] acho cansativo porque é muita coisa e ganha pouco [...] É bom mas é uma área muito rotineira e isso cansa e por isso tenho interesse em conhecer outras áreas na empresa. Eu entrei na empresa em outra área, na central de cópias, lá todos são deficientes, mas não tem crescimento, é uma área muito restrita.

O desgaste psíquico pode ser observado ainda em algumas vivências produzindo sentimentos de constrangimento, que, se devidamente apuradas, poderiam inclusive, configurar situações de assédio moral, aqui entendido como uma exposição do trabalhador a situações humilhantes e constrangedoras, repetitivas e prolongadas durante a jornada de trabalho e no exercício de suas funções; com o predomínio de condutas negativas e relações desumanas (BARRETO, 2003). 
As pessoas não confiam muito na gente, no meu caso, não deixam serviço para eu executar. Embora tenhamos limitações físicas, mental não temos nada, por isso deveríamos fazer tudo que todos fazem [...] Ainda tenho dificuldade em alguma reunião, de informar, avisar que não estou conseguindo participar, preciso perder um pouco da vergonha $[. .$.

Sobre os constrangimentos e humilhações sofridos por trabalhadores com deficiência no ambiente organizacional, Siqueira e Oliveira-Simões (2008) verificaram sentimentos contraditórios, justificando intervenções nas políticas de gestão visando minimizá-los. Discutem que, apesar da revolta em função de tratamentos diferenciados e de constrangimentos cotidianos a que são submetidos, inclusive em termos de violência moral explícita, os indivíduos com deficiência consideram que um dos principais motivos dessa situação é a falta de conhecimento da sociedade quanto à capacidade, qualificação profissional e credibilidade no trabalho deles.

\section{Reconhecimento no trabalho}

Em relação à categoria reconhecimento social no trabalho, as vivências de falta de reconhecimento desses trabalhadores com deficiência expressam certa mágoa com a empresa e/ou gestores e pessoas, remetendo à importância da disseminação de medidas que assegurem a conscientização sobre os direitos da pessoa com deficiência, como consta no artigo $8^{\circ}$, letra a, alínea iii: "Promover o reconhecimento das habilidades, dos méritos e das capacidades das pessoas com deficiência e de sua contribuição ao local de trabalho e ao mercado laboral" (BRASIL, 2009, p. 1).

Infelizmente ainda sofremos preconceito. Muita gente diz que não tem, dizem que fazem inclusão e acham bonito, mas no fundo tem preconceito, como exemplo, não dar uma determinada tarefa para o deficiente trabalhador é um tipo de preconceito. No meu caso, eu acredito que a chefia nem sabe que esta tendo preconceito por não passar tarefas, mas tem.

Entretanto, há também vivências de reconhecimento e satisfação, gerando senso de autonomia e de competência, o que "contribui para o desenvolvimento e a consolidação da identidade individual e coletiva dos trabalhadores e, nesse sentido, agrega sentido humano ao trabalho" (FERREIRA, 2008 p. 53).

Nos sentimos valorizados estando trabalhando [...] A carga de serviço é grande, bem corrido, mas eu gosto bastante [...] Eu acho que hoje eu estou bem integrada, já estou a quatro anos na empresa, iniciei como auxiliar, fui assistente e hoje estou como analista, estou crescendo e acredito que a empresa está apostando no meu crescimento, eu acho que melhorou a minha adaptação nas minhas necessidades devido a minha deficiência [...] A primeira dificuldade que eu tive na época foi com o aparelho telefônico, e tive todo o apoio do serviço médico em comprar um aparelho diferenciado para mim.
Ferreira (2008, p. 45), ao discutir o papel fundamental do reconhecimento, demarca as diferentes perspectivas teóricas sobre esse tema apontando a concepção de reconhecimento da teoria psicodinâmica do trabalho.

Uma retribuição que se vivencia, sobretudo, no ní-
vel do simbólico. Situa-se no "coração" da dinâmica
prazer e sofrimento no trabalho. Um julgamento de
beleza (pares) e de utilidade (hierarquia, clientes).
Um olhar voltado mais para o trabalho do sujeito que
para a pessoa em si mesma.

Constata-se, ainda, que o tópico reconhecimento social comparece em inúmeros estudos que abarcam a psicodinâmica do trabalho (MENDES, 2004; 2007; 2008; BARROS; MENDES, 2003; FERREIRA, 2008), pois, segundo Dejours (2000, p. 13), “[...] nós encontramos sempre nos trabalhadores a expressão de uma queixa relativa à falta de reconhecimento". Barros e Mendes (2003, p. 67-68) comentam essa questão citando que o contexto organizacional pode ser:

[...] um fator desestruturante e desestabilizador da saúde psíquica do indivíduo, gerando sofrimento, à medida que restringe ou extingue a liberdade de expressão de sua individualidade e a tomada de decisão, com base no não reconhecimento ou valorização de seu trabalho. Ao contrário, quando a organização do trabalho permite ao trabalhador a expressão da sua individualidade e subjetividade, propicia a elaboração e ressignificação do sentido do trabalho, por meio da transformação de situações de desgaste e sofrimento em situações de reconhecimento e prazer.

Há respostas divergentes sobre as relações sociais, como referências de convivência saudável desses deficientes com alguns gestores, ilustradas na fala: "O responsável pela área nos trata como amigo". Por outro lado, há também um relato de "vivência de injustiça e de sofrer em silêncio", indicando que o ambiente organizacional ainda comporta contradições em relação à percepção sobre o indivíduo com deficiência. Um diagnóstico sobre essas percepções nesse contexto, abarcando todo o universo de trabalhadores com deficiência, pode de ser de grande valor para nortear as práticas de gestão de pessoas, conforme orientação de Coimbra e Goulart (2008).

Outrossim, ressalta-se o quanto esses trabalhadores são capazes de contribuir com as políticas de gestão, se forem ouvidos em relação às suas necessidades. Entrevê-se aqui, a possibilidade da transformação do sofrimento rumo à emancipação desse trabalhador.

Eu acho que, para o meu posto de trabalho atual, atender e receber hoje mais um deficiente auditivo, ele é complicado, porque hoje a gente trabalha em uma sala aberta com 20 pessoas e, para nós recebermos outro deficiente auditivo, é necessário um lugar mais reservado, com poucos ruídos, principalmente o toque do telefone viva-voz, incomoda muito. 
Trata-se da questão da cooperação salientada por Dejours, quando citado por Mendes (2008, p. 23):

[...] como uma inteligência prática compartilhada e o espaço de deliberações, que implica o trabalho vivo. A inteligência individual, ou seja, a engenhosidade contribui para a ressignificação do sofrimento, mas se não transformada em cooperação, não consegue produzir mudanças na organização do trabalho.

Estas sugestões, aparentemente óbvias em relação à gestão da diversidade, corroboram ainda a visão de Sato, Lacaz e Bernardo (2006) de que o trabalhador deve atuar como um protagonista.

Acho que deveria acontecer, não no dia da integração, mas um momento antes, uma orientação ao gestor na área, talvez o próprio consultor logo no início, para explicar que entrará uma pessoa com deficiência, que ele é igual a todos, mas explicar a limitação, porque os colegas de trabalhos talvez não saibam ajudar, não saibam dessas limitações, mas a equipe tem que estar preparada para recebê-lo [...] Acho que em reuniões e na integração do primeiro dia de trabalho poderiam colocar uma pessoa só para explicar melhor para os deficientes auditivos, por que são muitas informações para gente [...]

A necessidade e a importância desse protagonismo dos deficientes na transformação da gestão que ora se pratica é ainda demonstrada como segue.

Como sugestão de mudança, na minha opinião, seria interessante os deficientes se concentrarem somente em uma área e um próprio deficiente coordenasse essa área, para provar que a área dará certo e tem capacidade para isso, mas sei que os próprios deficientes não aceitariam isso, por que parece exclusão, preconceito, mas eu acho legal, por que assim conseguiríamos mostrar o que essa área de deficientes pode fazer sozinha [...] Acho interessante a empresa proporcionar palestras sobre os deficientes na semana da saúde, por exemplo, que é uma semana cheia de palestras com temas diversos, mas acho que não deveria ser voltado só para os deficientes em si e sim para os outros funcionários.

\section{Estratégias de enfrentamento}

Em relação ao enfrentamento das situações adversas, observa-se a presença de estratégias defensivas minimizando o sofrimento causado pelas situações de trabalho geradoras de conflito (DEJOURS, 1992; DEJOURS; ABDOUCHELY, 1994), como as percepções sobre deficiência com as quais se confrontam no cotidiano do trabalho.

Nós com deficiência já somos retraídos, por isso não pode nos isolar. Acho que somos mais retraídos por que ninguém nos enxerga normal, quando fazemos alguma atividade, muitos pensam ou dizem: Nossa, como você conseguiu sendo deficiente? Nós fazemos o que conseguimos, ninguém vai fazer algo que não consegue, então não tem por que se espantar [...] Trabalhar aqui ajudou a aceitar a minha deficiência, até o uso do aparelho, a vergonha, a aceitação da deficiência como profissional, aceitação de saber dizer não estou escutando, desculpa, principalmente me olhar no espelho e falar, sou deficiente auditiva, e ai?
Talvez se eu não tivesse a oportunidade de trabalhar em uma indústria grande, hoje eu ainda não estaria tão desenvolvida [...] Acho que todo mundo tem uma deficiência, por isso nunca concordei com o termo portador, por que a impressão que tínhamos é que estávamos portando algo, parecia ser contagioso e nós temos a deficiência, não é contagioso.

Essas vivências podem ser vistas como sublimação, um processo inconsciente fundamental na estruturação da subjetividade desse sujeito-trabalhador, pressupondo uma negociação bem-sucedida entre o desejo e a realidade, "não implicando resistências a mudanças, passividade e conformismo, mas favorecendo a transformação do sofrimento advindo de uma organização do trabalho adversa". (MENDES, 2008, p. 18).

Estas estratégias defensivas remetem a vivências singulares, expressas e experimentadas cada uma ao seu modo, mas, embora sejam individualizadas, há vivências comuns entre eles que podem evoluir para uma vivência coletiva, pois "vários sujeitos experimentando cada um por si um sofrimento único seriam capazes de unir seus esforços para construir uma estratégia defensiva comum" (DEJOURS; ABDOUCHELY, 1994, p. 128). Ou seja, a estratégia de defesa coletiva se sustenta pelo consenso sobre a percepção da realidade operando por retorno e eufemização, como anunciado neste relato:

Sei que ainda tem muito preconceito, percebo isso com os olhares e os meus amigos deficientes também dizem isso [...] Fico triste apenas por que eu sei que poderia contribuir mais. [...] Acham que quem tem o corpo perfeito vai render mais, mas na verdade nem sempre é assim. Esse tipo de coisa eu tenho que aceitar, mesmo não concordando, por que é fato. Alguns ficam revoltados com essa situação.

Além de refletirem como enfrentam as situações adversas no trabalho, estas estratégias se constituem elementos de participação sociopolítica desse grupo, uma forma de evitar o isolamento social e sua importância no realinhamento da percepção da própria deficiência. Remetem ao processo de reconhecimento do seu trabalho, o que "implica uma mobilização política e a capacidade de construir e modificar a realidade do trabalho. Relaciona-se diretamente ao poder do trabalhador, compreendido como a capacidade de negociar e de influir no coletivo e trabalho" (MENDES, 2008, p. 19).

\section{Em última instância:}

[...] o processo de análise do sofrimento beneficia os sujeitos, pois produz sentido no lugar das defesas, isto é, torna possível um processo de reapropriação do sofrimento e da inteligibilidade das vivências subjetivas. (DEJOURS; ABDOUCHELY, 1994, p. 116)

Nesse sentido, supõe-se que a atitude de mobilização subjetiva desses trabalhadores não seja ainda su- 
ficiente, de fato, para que se afirmem enquanto sujeitos, reforçando sua identidade pessoal e profissional.

Considerando a gestão das pessoas nesta organização, é certo que a empresa realiza uma ação afirmativa no que se refere aos trabalhadores com deficiência, na medida em que trabalha com a Lei de Cotas, todavia, essas vivências indicam ainda não acolher as diferenças como prática inclusiva emancipatória desses indivíduos, tampouco como possibilidade de diferencial competitivo. Lembrando Ribeiro e Ribeiro (2008, p.138), a empresa, além de uma instituição econômica, deve ser vista como instituição social, oferecendo "um espaço processual e relacional marcado pelo trabalho como emancipação [...] podendo, inclusive, ser base para políticas públicas de promoção da diversidade”.

Tomando-se como referência as matrizes de interpretação sobre as concepções de deficiência elencadas por Carvalho-Freitas e Marques (2008, p. 246-248), esse contexto reflete, a partir do discurso dos pesquisados, uma visão da deficiência apoiada apenas no pressuposto de subsistência/sobrevivência. Ou seja, realiza-se uma ação de inclusão ou de exclusão para propiciar a manutenção da sociedade, mas a um alto custo, pois é uma "integração mediante comprovação de contribuição social efetiva, através do trabalho [...] Esta é uma condição de inserção social a que está sujeita a maioria das pessoas”. Nesse sentido, gera um grande ônus por terem sempre que comprovar sua condição. Portanto, mostra-se importante diagnosticar a concepção de deficiência predominante na organização pelos seus impactos diretos na gestão do trabalho das pessoas, almejando o alinhamento de expectativas, oportunidades e satisfação entre as partes, além do cumprimento das medidas oficiais previstas no Artigo 8, sobre Trabalho e Emprego, resguardando "o direito das pessoas com deficiência ao trabalho, em igualdade de oportunidades com as demais pessoas" (BRASIL, 2009, p. 17).

Constata-se, portanto, que os resultados desta investigação corroboram os dados da literatura nacional e internacional indicando a necessidade de replanejamento do trabalho nas organizações; no conteúdo, nas condições de trabalho e na natureza das relações sociais (SATO, 2002), por vezes antagônicos em relação às características do trabalhador com deficiência, mas que ainda coexistem no mercado formal.

\section{Considerações finais}

A análise das vivências subjetivas dos trabalhadores com deficiência relacionada às atividades de trabalho que realizam junto ao mercado formal permite tecer duas direções de conclusões. A primeira, sobre esses trabalhadores, e a segunda, referente à empresa.
Há indicativos de que para esses trabalhadores a deficiência é percebida como impedimento ao crescimento profissional, fator que por si só, pode remeter ao sofrimento psíquico, notadamente em termos da falta de reconhecimento no trabalho e de desgaste físico/psíquico.

As atividades que desempenham retratam uma organização de trabalho marcadamente regulada por controles, ritmo, pressão e hierarquia que dificultam o acolhimento das singularidades desses trabalhadores. A convivência entre eles nesse contexto é precária, dificultando o compartilhamento dos conflitos intersubjetivos e intra-subjetivos frente à realidade do trabalho, podendo explicar a falta de um coletivo de trabalho organizado para enfrentar o sofrimento.

O desgaste físico e/ou psíquico foi recorrente nos relatos desse grupo, vivenciado como desproteção, preconceito, medo, monotonia e constrangimentos, favorecendo a emergência de estratégias defensivas mais associadas à precária percepção do contexto sobre a deficiência e à qual atribuem responsabilidade pelo seu baixo status profissional. Uma vez que essa percepção reflita o reconhecimento do seu trabalho, facilitará reconhecerem-se enquanto profissionais, ou seja, a atividade do trabalho lhes conferirá pleno sentido. Portanto, conclui-se que mesmo o trabalho comparecendo como elemento estruturante da identidade desse grupo, as vivências de sofrimento sugerem se sobrepor às de prazer.

Nesse sentido, salienta-se a importância do deslocamento das práticas de gestão dessa empresa, centrada na adaptação das condições objetivas do contexto de trabalho, para uma prática que contemple as diferenças, dando igualdade de oportunidades, e enfatizando os aspectos subjetivos das vivências deste trabalhador em relação ao seu fazer. Com certeza desejam manifestar seus limites e potencialidades, acreditando na possibilidade de convergência entre suas necessidades e as da empresa. Considera-se que a explicitação desse sofrimento deva ser tomada como uma ação política em relação à organização do trabalho, visando à transformação teórico-prática da gestão de pessoas em uma gestão da diversidade.

Parece oportuno realizar outras investigações para dimensionar a questão do sofrimento entre esses trabalhadores e aqueles sem a deficiência, bem como em variados contextos de trabalho e com vistas à promoção de sua saúde, no sentido dejouriano, de liberdade de acesso aos meios para traçar um caminho pessoal e original, em direção ao bem-estar físico, psíquico e social. 


\section{Contribuições de autoria}

Leão, M. A. B. G.: orientação do projeto de pesquisa e produção desta versão para publicação. Silva, L. S.: desenvolvimento da pesquisa, contribuição na elaboração e aprovação final da versão.

\section{Referências}

ALMEIDA, L. A. D.; CARVALHO-FREITAS, M. N.; MARQUES, A. L. Análise comparativa das percepções das pessoas com deficiência em relação à inserção no mercado formal de trabalho. In: CARVALHO-FREITAS, M. N.; MARQUES, A. L. (Org.). Trabalho e Pessoas com Deficiência: pesquisas, práticas e instrumentos de diagnóstico. 2. ed. Curitiba: Juruá, 2008. p. 55-70.

ANTLOGA, C. S.; MENDES, A. M. Sofrimento e adoecimento dos vendedores de uma empresa de material de construção. Psicologia: Teoria e Pesquisa, v. 25, n. 2, p. 255-262, 2009.

BARDIN, L. Análise de conteúdo. Lisboa, Portugal: Edição 70, 1977.

BARRETO, M. Violência, saúde e trabalho: uma jornada de humilhações. São Paulo: Educ, 2003.

BARROS, P. C. R.; MENDES, A. M. B. Sofrimento psíquico no trabalho e estratégias dos operários terceirizados da construção civil. Psico-USF, v. 8, n. 1, p. 63-70, 2003.

BRASIL. Decreto nº 6.949, de 25 de agosto de 2009 . Promulga a Convenção Internacional sobre os Direitos das Pessoas com Deficiência e seu Protocolo Facultativo, assinados em Nova York, em 30 de março de 2007. Disponível em: < http:/www.planalto.gov.br/ ccivil 03/ ato2007-2010/2009/decreto/d6949.htm>. Acesso em: 02 maio 2012.

BRASIL. Lei no 8.213, de 24 de julho 1991. Dispõe sobre os Planos de Benefícios da Previdência Social e dá outras providências, 1991. Disponível em: <http:// www6.senado.gov.br/legislacao/ListaTextoIntegral. action?id=75662>. Acesso em: 15 set. 2010.

CARVALHO-FREITAS, M. N. Inserção e gestão do trabalho de pessoas com deficiência: um estudo de caso. RAC, Curitiba, v. 13, p. 121-138, 2009. Edição Especial. Disponível em: <http://www.anpad.org.br/ rac $>$. Acesso em: 18 maio 2010 .

CARVALHO-FREITAS, M. N.; MARQUES, A. L. Concepções de deficiência: as formas de ver a deficiência e suas consequências no trabalho. In: CARVALHO-FREITAS, M. N.; MARQUES A.L. (Org.). Trabalho e pessoas com deficiência: pesquisas, práticas e instrumentos de diagnóstico. 2. ed. Curitiba: Juruá, 2008, p. 237-252.

COIMBRA, C. E. P.; GOULART, I. B. Análise da inserção das pessoas com deficiência segundo suas percepções. In: CARVALHO-FREITAS, M. N.;
MARQUES A. L. (Org.). Trabalho e pessoas com deficiência: pesquisas, práticas e instrumentos de diagnóstico 2. ed. Curitiba: Juruá, 2008, p. 106-121.

DEJOURS, C. Por um novo conceito de saúde. Revista Brasileira de Saúde Ocupacional, São Paulo, v. 14, n. 54, p. 7-11, abr./jun. 1986.

. A loucura do trabalho: estudo de psicopatologia do trabalho. São Paulo: Cortez-Oboré, 1992.

Préface. In: CARPENTIER-ROY, M. C; VEZINA, M. (Org.). Le travail et ses malentendus. Psychodynamique du travail et gestion. Toulouse: Octarès, 2000, p.13.

A metodologia em psicodinâmica do trabalho. In: LANCMAN, S.; SZNELWAR, L. I. (Org.). Christophe Dejours: da psicopatologia à psicodinâmica do trabalho. 3. ed. Brasília: Paralelo 15; Rio de Janeiro: Fiocruz, 2011a. p. 125-150.

. Sofrimento prazer no trabalho: a abordagem da psicopatologia do trabalho. In: LANCMAN, S.; SZNELWAR, L. I. (Org.). Christophe Dejours: da psicopatologia à psicodinâmica do trabalho. 3. ed. Brasília: Paralelo 15; Rio de Janeiro: Fiocruz, 2011b. p. 167-183.

DEJOURS, C.; ABDOUCHELY, E. Itinerário teórico em psicopatologia do trabalho. In: DEJOURS, C.; ABDOUCHELY, E.; JAYET, C. Psicodinâmica do trabalho. São Paulo: Atlas, 1994, p. 120-145.

FERREIRA, M. C. Chegar feliz e sair feliz do trabalho: aportes do reconhecimento no trabalho para uma ergonomia aplicada à qualidade de vida no trabalho. In: MENDES, A.M. (Org.) Trabalho e saúde: o sujeito entre emancipação e servidão. 2. ed. Curitiba: Juruá. 2008, p. 40-53.

INSTITUTO BRASILEIRO DE GEOGRAFIA E ESTATÍSTICA. Censo Demográfico: resultados preliminares de la muestra. IBGE, 16 nov. 2011. Disponível em: <http://www.ibge.gov.br/espanhol/ presidencia/noticias/noticia visualiza.php?id noticia $=2018 \& i d$ pagina $=1>$. Acesso em: 02 maio 2012 .

JACQUES, M. G. C. Abordagens teórico-metodológicas em saúde/doença mental \& trabalho. Psicologia \& Sociedade, v. 15, n. 1, p. 97-116, 2003.

LIMA JÚNIOR, J. H. V.; ESTHER, A. B. Transições, prazer e dor no trabalho de enfermagem. RAE - Revista 
de Administração de Empresas, São Paulo, v. 41 n. 3, p. 20-30, 2001.

MENDES, A. M. Cultura organizacional e prazer-sofrimento no trabalho: uma abordagem psicodinâmica. In: TAMAYO, A. (Org.). Cultura e saúde nas organizações. São Paulo: Artmed, 2004, p. 53-69.

Da Psicodinâmica à psicopatologia do trabalho. In: MENDES, A. M. (Org.). Psicodinâmica do trabalho: teoria, método e pesquisas. São Paulo: Casa do Psicólogo, 2007, p.7-16.

. Prazer, reconhecimento e transformação do sofrimento no trabalho. In: MENDES, A.M. (Org.) Trabalho e saúde: o sujeito entre emancipação e servidão. 2. ed. Curitiba: Juruá. 2008, p. 13-25.

MENDES, A. M.; MORRONE, C. F. Vivências de prazer-sofrimento e saúde psíquica no trabalho: trajetória conceitual e empírica. In: MENDES, A. M.; BORGES, L. O.; FERREIRA, M. C. (Org.). Trabalho em transição, saúde em risco. Brasília: UnB, 2002, p. 4257.

MENDES, A. M.; MORRONE, C. F. Vivências de prazer-sofrimento e saúde psíquica no trabalho: trajetória conceitual e empírica. In: MENDES, A. M.; FERREIRA, M. C. (Orgs.). Trabalho em transição, saúde em risco. Brasília: Editora Universidade de Brasília, 2004. p. 27-42.

MERLO, A. R. C.; MENDES, A. M. B. Perspectivas do uso da psicodinâmica do trabalho no Brasil: teoria, pesquisa e ação. Cadernos de Psicologia Social e do Trabalho, v.12, n. 2, p.141-156, 2007.

NOHARA, J. J.; ACEVEDO, C. R.; FIAMMETTI, M. Avida no trabalho: as representações sociais das pessoas com deficiências. In: CARVALHO-FREITAS, M. N.; MARQUES; A. L. (Org.). Trabalho e pessoas com deficiência: pesquisas, práticas e instrumentos de diagnóstico. 2. ed. Curitiba: Juruá, 2008, p.71-88.

OLIVEIRA, J. M.; ARAÚJO, J. N. G.; ROMAGNOLI, R. C. Dificuldades relativas a inclusão social das pessoas com deficiências no mercado de trabalho. LatinAmerican Journal of Fundamental Psychopathology on Line, v. 3, n. 1, p. 77-89, 2006. Disponível em: < http:// www.fundamentalpsychopathology.org/uploads/ files/latin_american/v3_n1/dificuldades_relativas_a_ inclusao_social_das_pessoas_com_deficiencia_no_mercado_do_trabalho.pdf $>$. Ācesso em: 24 maío 2012.

RIBEIRO, M. A.; RIBEIRO, F. Gestão organizacional da diversidade: um estudo de caso de um programa de inclusão com pessoas com deficiência. In: M. N. CARVALHO-FREITAS; A. L. MARQUES (Orgs.).
Trabalho e pessoas com deficiência: pesquisas, práticas e instrumentos de diagnóstico. 2. ed. Curitiba: Juruá, 2008, p.122-141.

SANTOS, G. B. As estratégias de fuga e enfrentamento frente às adversidades do trabalho docente. Estudos e Pesquisas em Psicologia, Rio de Janeiro, v. 6 n. 1, p.128-133, 2006.

SÃO PAULO (Estado). Secretaria dos Direitos da Pessoa com Deficiência. Sumário: Relatório Mundial sobre a Deficiência. São Paulo: SEDPcD, 2012.

Disponível em: <http:/whqlibdoc.who.int/hq/2011/ WHO_NMH_VIP_11.01_por.pdf $>$. Acesso em: 02 maio 2012.

SASSAKI, R. K. Inclusão: construindo uma sociedade para todos. 3. ed. Rio de Janeiro: WVA, 1999.

SATO, L. Prevenção de agravos à saúde do trabalhador: replanejando o trabalho através das negociações cotidianas. Cadernos de Saúde Pública, v. 18, n. 5, p. 1147-1166, 2002.

SATO, L.; LACAZ, F. A. C.; BERNARDO, M. E. Psicologia e saúde do trabalhador: práticas e investigações na Saúde Pública de São Paulo. Estudos de Psicologia, v. 11, n. 3, p. 281-288, 2006.

SECRETARIA INTERNACIONAL DO TRABALHO. Gestão de questões relativas à deficiência no local de trabalho: repertório de recomendações práticas da OIT -Organização Internacional do Trabalho. Tradução de Edilson Alkmin Cunha. Brasília: OIT, 2006.

SELIGMANN-SILVA, E. A inter-relação trabalho-saúde mental: um estudo de caso. Revista de Administração de Empresas, São Paulo, v. 32, n. 4, p. 70-90, 1992.

et al. O mundo contemporâneo do trabalho e a saúde mental do trabalhador. Revista Brasileira de Saúde Ocupacional, São Paulo, v. 35, n. 122, p. 187191, 2010.

SIQUEIRA, M. V. S.; OLIVEIRA-SIMÕES, J. T.

Violência moral e pessoas com deficiência: constrangimentos e humilhações no ambiente de trabalho. In: CARVALHO-FREITAS, M. N.; MARQUES, A. L. (Org.). Trabalho e pessoas com deficiência: pesquisas, práticas e instrumentos de diagnóstico. 2. ed. Curitiba: Juruá, 2008, p.187-199.

SUZANO, J. C. C. et al. Análise da produção acadêmica nacional dos últimos 20 anos sobre a inserção da pessoa portadora de deficiência no mercado de trabalho. In: CARVALHO-FREITAS, M. N.; MARQUES, A. L. (Orgs.). Trabalho e pessoas com deficiência: pesquisas, práticas e instrumentos de diagnóstico. 2. ed. Curitiba: Juruá, 2008. p. 23-41. 